\title{
Desempenho horticultural de plantas propagadas in vitro de Sacha inchi.
}

\author{
Horticultural performance of in vitro propagated plants of Sacha inchi.
}

\author{
Paulo Hercílio Viegas Rodrigues ${ }^{\mathrm{I}}$ Stevan Ricardo Bordignon $^{\mathrm{I}}$ Glaucia Maria Bovi Ambrosano ${ }^{\mathrm{II}}$
}

\section{- NOTA -}

\section{RESUMO}

O objetivo do presente trabalho foi avaliar, em condições de campo, características horticulturais de mudas propagadas in vitro de Sacha inchi (Plukenetia volubilis $L$ ), quanto à época de florescimento e colheita, características morfológicas relacionadas à coloração e forma de folhas, caule e frutos, bem como a produtividade do material propagado in vitro. As mudas de cultura de tecidos foram propagadas por seis semanas em meio de cultivo com sais e vitaminas de MS, acrescido de $30 \mathrm{~g}^{-1}$ de sacarose e $1,0 \mathrm{mg} L^{-1}$ de BAP, a partir do ponteiro de plântula germinada in vitro. Foram selecionadas, ao acaso, quatro plantas propagadas in vitro, quatro plantas por via seminal e mais vinte e duas plantas, também por via seminal, compondo a bordadura, totalizando trinta plantas. As análises foram semanais até completar quatorze meses do plantio, que ocorreu antes da primeira poda. Os resultados obtidos indicam a não ocorrência de variabilidade genética nas plantas produzidas in vitro, bem como precocidade na produção e maior produtividade, quando comparado com o material convencional obtido via seminal.

Palavras-chave: ômega 3, Plukenetia volubilis L., euforbiácea, variação somaclonal.

\section{ABSTRACT}

The aim of this study was to evaluate, in the field, the horticultural characteristics of Sacha inchi (Plukenetia volubilis L.) in vitro plants considering time of flowering and harvesting, the productivity, as well as their morphological characteristics: color and shape of leaves, stems and fruits. The plantlets, originated from the apex of in vitro plants, were propagated in culture medium with MS salts and vitamins, add $30 \mathrm{~g} \mathrm{~L}^{-1}$ sucrose and $1.0 \mathrm{mg} \mathrm{L}^{-1}$ BAP for six weeks. Were selected at random, four plants propagated in vitro, four plants by seminal and twenty-two plants, also by composing the border, totaling thirty plants. Analyses were completed weekly until fourteen months after planting, which occurred before the first pruning. The results indicate the non-occurrence of genetic variability in vitro grown plants, as well as early in the production and increased productivity as compared with the conventional material obtained via seminal.

Key words: omega 3, Plukenetia volubilis, Euphorbiaceae, Somaclonal variation.

Conhecida pelos povos andinos a milhares de anos, a euforbiácea Plukenetia volubilis Linneo é nativa da região Amazônica, compreendendo os países do Peru, Colômbia, Venezuela e Brasil. Essa trepadeira perene se adapta a solos ácidos e argilosos, altitude de 0 a $1200 \mathrm{~m}$ e tem melhor desenvolvimento em clima quente. As flores são unissexuadas e dispostas em inflorescências racemosas. Trata-se de uma planta monoica e, apesar de ser possível a autofecundação, há uma grande porcentagem de fecundação cruzada. A semente oval e de coloração marrom escura é a estrutura de maior interesse na planta. Por ser rica em proteínas, vitamina E, e principalmente em óleos poli-insaturados ômegas 3, 6 e 9, em maior concentração até que em outras oleaginosas, ela apresenta um grande potencial agro tecnológico e atualmente é largamente explorada por indústrias peruanas na produção de seu azeite. No Peru, a cultura é conhecida como Sacha inchi. O azeite destina-se tanto ao consumo humano, na forma de suplemento alimentar, como também na indústria

\footnotetext{
ILaboratório de Cultura de Tecidos de Plantas Ornamentais, Escola Superior de Agricultura Luiz de Queiroz, Universidade de São Paulo (USP), Av. Pádua Dias, 11, CP 09, 13418-900, Piracicaba, SP, Brasil. E-mail: phrviegas@usp.br. *Autor para correspondência.

IIDepartamento de Odontologia Social, Faculdade de Odontologia de Piracicaba, Universidade Estadual de Campinas (UNICAMP), Bioestatística, Piracicaba, SP, Brasil.
} 
cosmética, possuindo um bom mercado tanto interno quanto externo (CÉSPEDES, 2006). O controle de triglicérides pós-prandial foi comprovado em adultos jovens que consumiram o equivalente a $11 \mathrm{~g}$ do azeite de Pluketeia volubilis. O alto teor de ômega 3 presente no óleo, descrito por GUILLÉN et al. (2003), foi o responsável pela redução dos teores de triglicerídeos (HUAMÁN et al., 2008). Estudo comparativo entre os óleos obtidos do Sacha inchi e da Linhaça, utilizando técnicas de ressonância magnética nuclear e espectroscopia (FTIR), demonstrou maior teor de ômega 3 em Plukenetia volubilis L. (GUILLÉN et al., 2003). A espécie se propaga principalmente por via seminal, o que ocasiona um plantio desuniforme e dificulta a expansão das áreas de plantio. Em cultura de tecidos, BORDIGNON et al. (2012) utilizaram segmentos distintos de hipocótilo e epicótilo de sementes germinadas in vitro de Sacha inchi e obtiveram mudas a partir do segmento apical em meio de cultivo MS, na concentração de $1,0 \mathrm{mgL}^{-1} \mathrm{da}$ citocinina BAP (benzilaminopurina). A ocorrência de variabilidade genética, decorrente do processo de cultivo in vitro foi observada nas culturas da banana, abacaxi ornamental e heliconia (SANTOS E RODRIGUES, 2004; RODRIGUES et al., 2006a; RODRIGUES, 2008). Essa variabilidade muitas vezes pode ser indesejada, afetando a produção como um todo e alterando características morfológicas da planta. O ensaio de campo para avaliar o desempenho das mudas produzidas por técnicas de cultura de tecidos é fundamental para determinar parâmetros de qualidade e aprimorar a técnica empregada na propagação in vitro. Diante disso, e da inexistência de trabalhos nessa área com mudas de Sacha inchi propagadas in vitro, o objetivo do presente trabalho foi avaliar a campo, características horticulturais das plantas produzidas por esta técnica.

O material utilizado foi de mudas de Sacha inchi obtidas a partir da propagação in vitro e por via seminal (convencional). As mudas de cultura de tecidos foram propagadas por seis semanas em meio de cultivo com sais e vitaminas de MS (MURASHIGE \& SKOOG, 1962), acrescido de $30 \mathrm{gL}^{-1}$ de sacarose e 1,0 $\mathrm{mgL}^{-1}$ de BAP, a partir do ponteiro de plântula germinada in vitro. $\mathrm{O}$ enraizamento foi em meio de cultivo com a metade da concentração de sais de MS, vitaminas de MS, acrescido de $30 \mathrm{gL}^{-1}$ de sacarose e $0,5 \mathrm{mgL}^{-1}$ de IBA (acido indolbutírico). As mudas enraizadas, no total de 15 plântulas, foram aclimatizadas em casa de vegetação, sombreamento de $50 \%$ e umidade de $90 \%$ por duas semanas e transplantadas em bolsa plástica $(15,0 \mathrm{cmx} 10,0 \mathrm{~cm})$, contendo substrato esterilizado BASE horticultura e mantidas em viveiro com sombreamento $50 \%$, sob irrigação até o plantio. Para obtenção das mudas convencionais, foram selecionadas 50 sementes, plantadas em bolsas plásticas $(15,0 \mathrm{~cm}$ x10,0cm) contendo substrato esterilizado BASE horticultura, mantidas nas mesmas condições acima citadas, até o plantio do ensaio. A germinação das sementes variou de duas a três semanas após a semeadura. Para o ensaio, foram selecionadas, ao acaso, quatro mudas propagadas in vitro, quatro mudas propagadas via seminal (controle) e mais vinte e duas mudas via seminal para compor a bordadura do ensaio, totalizando trinta mudas de Sacha inchi. O ensaio foi instalado no município de Piracicaba - SP, em fevereiro de 2012 com as mudas avaliadas plantadas de maneira alternada em área experimental de topografia plana, latosolo vermelho amarelo, altitude de 564m, clima, segundo Kopen, do tipo Cwa tropical de altitude, com inverno seco e temperatura no mês mais quente superior a $22^{\circ} \mathrm{C}$. O espaçamento utilizado foi de $2,0 \mathrm{~m}$ entre plantas e $2,5 \mathrm{~m}$ entre ruas. Foram utilizadas estacas de eucalipto com 1,5m acima do solo a cada 2,0m para tutoramento da cultura, que foi conduzida por fios de aço entre as estacas (número de três). As avaliações consistiram em observações semanais de características morfológicas (coloração de folhas, frutos e caule), início da floração, produção e da produtividade ( $\mathrm{kg}$ semente $\mathrm{s}^{-1}$ ) até o período da primeira poda, que ocorreu 14 meses após o plantio. Para análise estatística dos dados relativos à produtividade, foi utilizado o teste de $\mathrm{t}$ de Student (5\% de probabilidade). O plantio recebeu os tratos culturais como adubação, irrigação por aspersão e controle de ervas daninha (mecanizado).

Durante o desenvolvimento vegetativo, não foram observadas alterações morfológicas quanto à coloração de folhas e caule ou formas variadas nas folhas entre as mudas propagadas in vitro de Sacha inchi. Nas culturas da banana, abacaxi ornamental e em heliconias, foram relatadas alterações morfológicas em mudas propagadas in vitro que comprometeram a produção dessas culturas (SANTOS \& RODRIGUES, 2004; RODRIGUES et al., 2007; RODRIGUES, 2008). Em banana, o elevado número de subcultivo submetido aos explantes resultou em variantes somaclonais indesejáveis, com porte reduzido e má formação de cachos em bananeiras da cultivar Pacovan, obtidas de cultura de tecidos. No cultivo in vitro de abacaxi ornamental (Ananas bracteatus) em meio de cultivo MS líquido e concentração de 0,1 mg $\mathrm{L}^{-1}$ de 6-benziladenina (6-BA), os autores relataram 
alta variabilidade genética, mesmo com reduzida concentração de citocinina e poucos subcultivos in vitro, obtendo plantas com descaracterização das folhas quanto à coloração, o que inviabilizou a possibilidade de comercialização das mudas. Na propagação in vitro de heliconia (Heliconia bihai), as alterações morfológicas resultaram em plantas com hastes florais de coloração diferente à do mercado, dificultando sua colocação no mercado. Nesse caso, também o elevado número de subcultivos contribuiu para a ocorrência desse tipo de variação em heliconias. A avaliação em campo das mudas de Sacha inchi propagadas in vitro demonstrou que esta euforbiácea não apresentou variabilidade genética ou epigenética decorrente do processo in vitro, provavelmente pela reduzida concentração da citocinina BAP e curto período a que foram submetidos os explantes no sistema in vitro. No presente ensaio, o início da floração ocorreu a cinco meses do plantio e de maneira uniforme, apenas nas mudas produzidas in vitro. As mudas obtidas por via seminal iniciaram o florescimento após seis meses de plantio e de maneira desuniforme, com diferença de dois meses entre plantas. A produção das mudas in vitro acompanhou a precocidade e uniformidade da floração, ocorrendo há oito meses do plantio, enquanto que, nas mudas do controle, a produção ocorreu há nove meses do plantio e desuniforme. No ensaio de campo para avaliar mudas micropropagadas de heliconia (Heliconia bihai), comparando-as a mudas de rizoma, observou-se precocidade nas mudas produzidas pelo método convencional (rizoma) e tendência de maior produção nos primeiros meses de colheita. Foi constatado que o uso da citocinina BAP, durante o processo de propagação in vitro, aumentou o número de perfilhos nas mudas de cultura de tecidos e, no primeiro momento, retardou o início da produção de hastes em detrimento do maior número de perfilhos. Ao final da avaliação, o maior número de perfilhos do tratamento com mudas micropropagadas gerou mais hastes florais e foi superior em produtividade quando comparado ao método convencional na cultura de heliconia (RODRIGUES et al, 2006). No ensaio com Sacha inchi, a maior produtividade das mudas in vitro foi observada desde o início da colheita até a conclusão das avaliações, após 14 meses de plantio, obtendo média de 375,75g, contra 155,50g de sementes no tratamento em plantas obtidas por via seminal. A análise estatística pelo teste t (Student) demonstra diferença significativa a favor do tratamento de cultura de tecidos com $\mathrm{P}<0,0002$, como pode ser observado na figura 1. Esses resultados demonstram as vantagens da utilização de mudas obtidas de cultura de tecidos em plantios comerciais. Após ajustes nos protocolos de propagação in vitro, culturas como a do abacaxi, morango, banana, cana de açúcar, eucalipto e inúmeras plantas ornamentais beneficiam-se da cultura de tecidos, com consequências benéficas no cultivo, como uniformidade na produção, qualidade fitossanitária das mudas e muitas vezes precocidade na produção, que reflete em maior produtividade. No caso da cultura em estudo, a produtividade foi muito superior, quando comparado ao método convencional de propagação. A precocidade e uniformidade na produção são características desejáveis no agronegócio e no cultivo de Sacha inchi, uma cultura de alto valor agregado e com potencial para agricultura familiar, tais características foram constatadas.

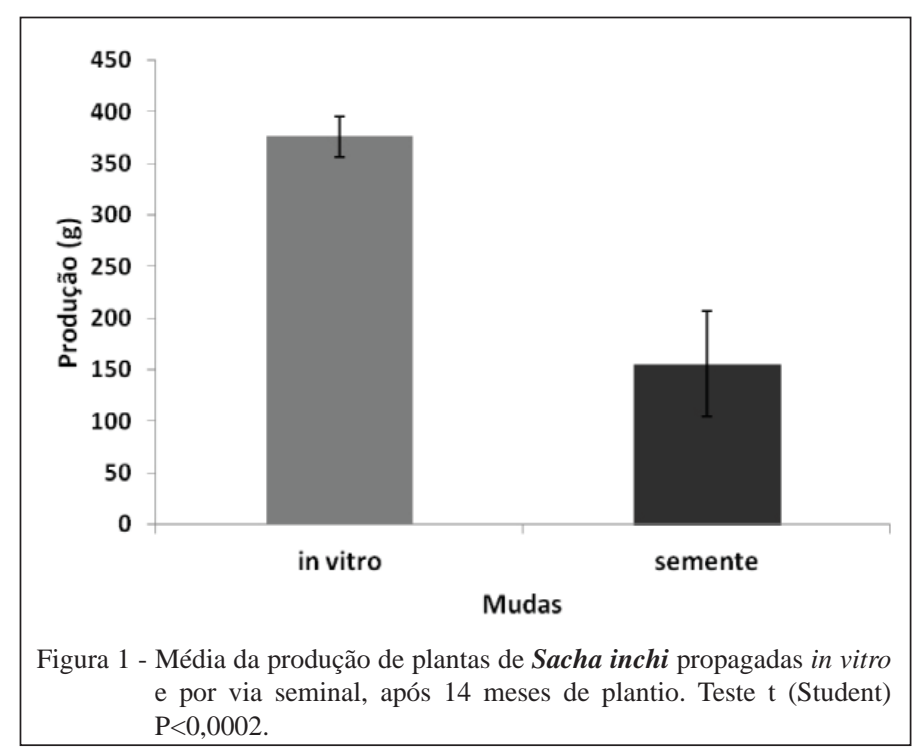

Ciência Rural, v.44, n.6, jun, 2014. 


\section{AGRADECIMENTOS}

Os autores agradecem a Fundação de Amparo à Pesquisa do Estado de São Paulo (FAPESP) (10/50335-0) pelo apoio financeiro, bolsa de IC do autor S.R Bordignon (10/17744-4) e a Dom Alcimar Caldas Magalhães (Diocese Alto Solimões - Tabatinga/AM)

\section{REFERÊNCIAS}

BORDIGNON, S.R. et al. Propagação in vitro de Sacha inchi (Plukenetia volubilis Linneo). Ciência Rural, v.42, n.7, p.11681172, 2012. Disponível em: <http://www.scielo.br/scielo. php?script=sci_arttext\&pid=S0103-84782012000700005\&lng=en \&nrm=iso>. Acesso em: 05 Feb. 2014. Doi: 10.1590/S010384782012005000049 .

CÉSPEDES, E.I.M. Cultivo de Sacha Inchi. Tarapoto, San Martin, Peru: INIIA, Subdirección De Recursos Geneticos Y Biotecnología, 2006. 11p.

GUILLÉN, M.D. et al. Characterization of Sacha Inchi (Plukenetia volubilis L.) oil by FTIR spectroscopy and ${ }^{1} \mathrm{H}$ NMR. Comparison with linseed oil. Journal of the American Oil Chemist Society, v.80, p.755-762, 2003. Disponível em: <http:// link.springer.com/article/10.1007\%2Fs11746-003-0768-z\#> Acesso em: 06 Feb. 2014. Doi: 10.1007/s11746-003-0768-z.

HUAMÁN, J. et al. Efecto de la Plukenetia volubilis Linneo (Sacha inchi) en la trigliceridemia posprandial. Annales Faculdad Medicina, v.69, p.263-266, 2008.
MURASHIGE, T.; SKOOG, F. A revised medium for rapid growth and bioassays with tobacco tissue cultures. Physiologia Plantarum, v.15, p. 473-497, 1962.

RODRIGUES, P.H.V. et al. Heliconia bihai var. Lobster Claw I: cut flower field production from micropropagated- versus rhizome-derived plants. In: SILVA da, J.A.T. (Org.). Floriculture, ornamental and plant biotechnology: advances and topical issues. Londres: Global Science Books, 2006. V.2, p.558-560.

RODRIGUES, P.H.V. et al. Variação somaclonal em mudas micropropagadasdeabacaxiornamental, Ananas Bracteatus Schultes var. Striatus. Revista Brasileira de Horticultura Ornamental, v.12, n.2, p.122-125, 2007. Disponível em: <http://132.248.9.34/ hevila/Revistabrasileiradehorticulturaornamental/2006/vol12/no2/8. pdf.> Acesso em: 06 Feb. 2014.

RODRIGUES, P.H.V. Somaclonal variation in micropropagated Heliconia bihai cv. Lobster Claw I Plantlets (Heliconiaceae). Scientia Agricola, v.65, p.681-684, 2008. Disponível em: $<$ http://www.scielo.br/scielo.php?script=sci_arttext\&pid=S010390162008000600017\&lng=en\&nrm=iso >. Acesso em: 06 Feb. 2014. Doi: 10.1590/S0103-90162008000600017.

SANTOS, C.C.C.; RODRIGUES, P.H.V. Ocorrência de variação somaclonal em mudas de bananeira micropropagadas da cultivar Pacovan (Musa spp., grupo AAB). Revista Bragantia, v.63, n.2, p.201-205, 2004. Disponível em: <http://www.scielo.br/scielo. php?script=sci_arttext\&pid=S0006-87052004000200005\&lng =en\&nrm=iso>. Acesso em: 06 Feb. 2014. Doi: 10.1590/S000687052004000200005. 